DOI: https://doi.org/10.33739/2587-5434-2019-106-114

\author{
Anna Petrikova \\ Ph.D, Assistant Professor \\ Preshov University \\ (Preshov, Slovaky) \\ e-mail: anna.petrikova@unipo.sk
}

\title{
LINGUODIDACTIC PROBLEMS OF TEACHING CLOSE LANGUAGES
}

Abstract. The article deals with the problems of mastering a foreign language as a result of the influence of the native language on a foreign one. While comparing the content and formal aspects of the lexical units of both languages, the following phenomena can be identified: matching in both languages; partially matching and non-matching. The linguodidactic description of the lexical units of the Slovak and Russian languages is based on the linguistic statement about the word as a sign unit that has a plan of content (sememe) and form (lexeme). The most common type is interlingual interference which is manifested in the process of mastering the Russian language. On the basis of the onomasiological approach, the article examines some possibilities of transferring the paradigm of the native language to a foreign one.

Key words: asymmetry, bilingualism, lexical interference, language contacts

\author{
Анна Петрикова \\ Доктор философии, ассистент профессор \\ Прешовский университет \\ (Прешов, Словакия) \\ эл-почта: anna.petrikova@unipo.sk
}

\section{ЛИНГВОДИДАКТИЧЕСКИЕ ПРОБЛЕМЫ ПРЕПОДАВАНИЯ БЛИЗКОРОДСТВЕННЫХ ЯЗЫКОВ}

\begin{abstract}
Аннотация: В данной статье рассматриваются проблемы усвоения иностранного языка в результате влияния родного языка на изучаемый. При сопоставлении содержательной и формальной сторон лексических единиц обоих языков можно выявить следующие явления: совпадающие в обоих языках; частично совпадающие в языках и несовпадающие в обоих языках. В основе лингводидактического описания лексических единиц словацкого и русского языков лежит лингвистическое положение о слове как знаковой единице, которая имеет план содержания (семема) и формы (лексема). Самым распространенным типом является межъязыковая интереференция, к которой принадлежит и лексическая интереференция, которая проявляется в процессе усвоения русского языка. На основе ономасиологического подхода в статье рассморены некоторые возможности переноса парадигмы родного языка в иностранный.
\end{abstract}

Ключевые слова: асимметрия, билингвизм, лексическая интерференция, языковые конmakmbl 


\section{ВВЕДЕНИЕ \\ ИЗУЧЕНИЕ РУССКОГО ЯЗЫКА В СЛОВАКИИ}

Преподавание русского языка и литературы в словацкой системе образования традиционно исходит из генетической взаимосвязанности русского и словацкого языков. Принцип родства славянских языков и типологической близости имеют значительное влияние на усвоение фонетики, лексики, грамматики в процессе обучения. При лингводидактическом описании языковых единиц соблюдается принцип лингвистического сопоставительного описания. Процесс обучения обычно начинается с нулевой ступени овладения неродным языком, но данный процесс не такой трудный в силу того, что слова общеславянского языка до сих пор используются и в русском и в словацком языках. В данную группу входят слова типа: отец, сестра, брат, вода, гора, камень, нос, рука, палеи, день, вечер, ночь, лето, зима, осень, снег, липа, дуб, тополь, соль, железо, сила, игла и т.П.. Данные и подобные им единицы представляют важную составляющую потенциальных ресурсов для рецептивных способностей, изучающих русский язык в словацких учебных заведениях.

Целью данной статьи является анализ выбранных проблем при усвоении словацкого как близкородственного языка, а именно возникновение лексической интерференции как результата контакта языков, а так же возможности предотвращения ошибок в иноязычном обучении.

Теоретическая основа исследования сформирована трудами Э. Хаугена, У. Вайнрайха, Ю. А.Жлуктенко, Л. В. Щербы, М. Рогаля.

Основным методом исследования является сопоставление характеристик лексических единиц в русском и словацком языках, при которых проявлятся интерференциия в процессе изучения русского языка как иностранного.

\section{МЕТОДОЛОГИЯ ИССЛЕДОВАНИЯ ЯЗЫКОВЫХ КОНТАКТОВ}

Взаимодействие близкородственных языков создает сложное явление языкового контакта (ЯК), который многообразно функционирует на разных уровнях языки и речи. Термин ЯК впервые предложил Андре Мартин (Haugen 1966). Значительный вклад в теорию языковых контактов внес У. Вайнрайх (Weinreich 1979). В ней он наметил общие направления в исследовании данного явления и на материале ряда языков рассмотрел случаи морфологической интерференции в связи с различной грамматической функцией морфем и вероятностью их перенесения из одного языка в другой.

Языковые контакты - это такая разнообразная деятельность, которая реализуется в процессе употребления языка. Ю.А. Жлуктенко в монографии «Языковые контакты» пишет по этому вопросу следующее: «Языковой контакт и взаимодействие языков отличаются друг от друга тем, что соотносятся как причина и следствие. Пока между двумя языками не установится тот или иной тип контакта, между ними не может быть никакого взаимодействия. Между двумя парами языков может установиться одинакового типа контакт, а взаимодействие между ними может приобретать разный характер, в зависимости от целого ряда лингвистических и внелингвистических факторов» (Zhlutenko 1966: 12). В процессе использования языка проявляется социальная сущность языка, процессуальность, изменение и функция языковой системы. 
Значительный вклад в упорядочение фундаментальных понятий теории языковых контактов внес А. Е. Карлинский, разграничив проявление результата языкового контактирования либо в речи билингва на одном из языков (речевая мутация), либо в языковой системе (языковая диффузия). А. Е. Карлинский выводит четыре аспекта взаимодействия языков (Karlinskij 1972: 7-8).

На языковые контакты могут влиять как лингвистические, так и экстралингвистические факторы. К лингвистическим факторам Ю.А. Жлуктенко относит: длительность и устойчивость ЯК (Zhlutenko 1966: 7-8); наличие/ отсутствие непосредственного ЯК (Zhlutenko 1974: 12); структурное соотношение контактирующих языков (Zhlutenko 1974: 18). К экстралингвистическим факторам ученый относит социологические, политические, экономические, культурные и этнические факторы (Zhlutenko 1974: 11). Таким образом, на языковые контакты влияет не только сама система языков, но и исторические, географические, общественно-политические, культурные, психологические факторы и условия пребывания билингва.

\section{БИЛИНГВИЗМ И ДВУЯЗЫЧИЕ}

В современной науке есть несколько направлений разграничения типов билингвизма. Представители одного из направлений считают самым существенным разделение внутрисубъектных типов билингвизма по параметру наличия либо отсутствия внутрисубъектной связи между двумя языковыми системами, или соотнесенности двух речевых механизмов между собой. Впервые такая классификация билингвизма была разработана Л. В. Щербой (Shcherba 1974), затем повторена У. Вайнрайхом (Weinreich 1999) независимо от первого. В дальнейшем предложенное Л. В. Щербой разделение двуязычия на чистое и смешанное стало пользоваться среди исследователей широкой популярностью. Сущность этого критерия в том, что обе языковые системы могут функционировать независимо друг от друга или могут быть связаны между собой во время акта речи. Если, например, билингв употребляет только одну языковую систему в определенной речевой ситуации (например, на работе), а в другой речевой ситуации (например, дома) - другую языковую систему, то на практике речевые механизмы никак не связаны друг с другом. В статье «К вопросу о двуязычии» (Shcherba 1974: 313-319) двуязычием Л. В. Щерба называет «способность тех или иных групп населения объясняться на двух языках» (Shcherba 1974: 313). Если «член двух взаимоисключающих друг друга групп никогда не имеет случая употреблять два языка вперемежку», то такое двуязычие Л. В. Щерба называет чистым. Таким образом, делается вывод, что носители этого типа билингвизма в определенной степени монолингвистичны, то есть способны пользоваться только одним языком в конкретной ситуации. Примером чистого билингвизма может быть случай, когда в семье используется один язык, а языком общения на работе, в магазине, транспорте других общественных местах является другой язык.

В иноязычном обучении чаще говорим об искусственном билингвизме. Для таких учащихся харатерно то, что они в основном изучают русский язык как иностранный язык в школе и вузе, а дома и на улице общаются на родном языке. Однако, в Словакии, на протяжении последних 5 лет, в связи с геополитической ситуацией в Украине, увеличилось количество учащихся из Украины. По данным агенства «Международная организация мигрантов» (он лайн) в 2017 году в Словакии находилось 104451 мигрантов, причем 
15,4 \% составляют жители Украины. Обучаемые из Украины владеют украинским языком, а также русским. В данном случае трудно говорить о двуязычии или билингвизме в чистом виде, поскольку украинский и русский языки оказываются родными, а словацкий - приобретенным. Скорее всего это вариант смешанного билингвизма, когда обе языковые системы связаны между собой во время акта речи. При «смешанном двуязычии» (Term of Shcherba), устанавливающемся в процессе самообучения, оба языка формируют в сознании говорящего лишь одну систему категорий таким образом, что любой элемент языка имеет тогда свой непосредственный эквивалент в другом языке. В этом случае отрицательное влияние одного языка на другой прогрессирует, захватывая все более широкие слои языка и приводя к образованию языка с одним планом содержания и двумя планами выражения. При несмешанном двуязычии усвоение второго языка происходит в процессе обучения, в ходе которого обучающемуся сообщаются правила установления соответствий между элементами родного и изучаемого языков и обеспечивается рациональная система закрепления этих соответствий в памяти. При нем влияние родного языка на изучаемый со временем постепенно ослабевает, уступая место правильному переключению от одного языка к другому.

\section{ЛЕКСИЧЕСКАЯ ИНТЕРФЕРЕНЦИЯ КАК ПРОДУКТ ЯЗЫКОВЫХ КОНТАКТОВ}

Понятие интерференции заимствовано из естественных наук. В лингвистике появляется в работах ученых Пражского лингвистического кружка, которые под интерференцией понимали «процесс отклонения от норм контактирующих языков» (Weinreich 1978: 22). Языковые контакты являются первоисточником интерференции. Более того, В.Ю. Розенцвейг (Rozencvejg 1963, 64) предлагает «принять за аксиому, что нет двуязычия без интерференции». Ю. О. Жлуктенко также считает интерференцию результатом ЯК и указывает на изменения в значениях, форме и структуре языковых единиц (Zhlutenko 1966).

Межъязыковая лексическая интерференция проявляется в том, что сходные по форме слова двух контактных языков (vôňa - заnax, zápach - вонь, zaschnutý - черствый, čerstvý - cвежuй) ошибочно воспринимаются носителями того и другого языка как семантически тождественные и употребляются в качестве эквивалента. При этом основанием для ошибочного вывода о тождественности семантического наполнения таких слов служит их звуковое сходство.

Межъязыковая лексическая интерференция может быть семантической и морфологической. Семантическая интерференция возникает в тех случаях, когда межъязыковые корреляты формально сходны, но не имеют вовсе или имеют только одно сходное значение, например: живот $\neq$ život $\rightarrow$ Живот в деревне ему надоел./Жизнь в деревне ему надоела.On obetoval svoj život/ жизнь - Он пожертвовал своей жизнью// brucho - Bolí ho brucho/живот - У него болит живот); родина $\neq$ rodina $\rightarrow$ Hаша родина cocтоит из четырёх человек. / Наша семья состоит из четырёх человек. Морфологическая же интерференция возникает в тех случаях, когда корреляты сходны по семантике, но не сходны формально, т. е. если конечный формант, вопреки ожиданиям аналогии с родным языком, с ним не совпадает, а оказывается другим, например: štvrtok $\rightarrow$ Приходи в четверток./ Приходи в четверг. 
Одной единице словацкого языка могут соответствовать несколько единиц русского языка или наоборот. В плане парадигматики и синтагматики у них разные возможности. Явление несовпадения семантики слова М. Рогаль называет «семантической ассиметрией» (Rogal' 1994: 81). Данные отношения семантической интерференции можно показать на следующих примерах:

ьој - бой, сражение, схватка, борьба; chodit'-ходить, ухаживать, ездить; list-лист, лепесток, страница, письмо, справка; рга́са - работа, служба, труд, занятия, дело.

К. И. Курбанова считает, что «механизм интерференции связан именно с проявлением асимметрии в языке и заключается в смешении формально подобных единиц одного (паронимия) или разных языков, которое приводит к нарушению языковой нормы» (Kurbanova 2012). Семантическая интереференция связана, прежде всего, с многозначностью слов.

Кроме межъязыковой интерференции выделяем внутриязыковую интерференцию, куда потносятся категория явлений, возникших под влиянием того же языка, например, под влиянием спряжения глаголов читать, -ю, -ешь; гулять, -ю, -ешь и по аналогии образованные неправильные формы глаголов: pисовать/pисоваю/pисоваешь, танцвать/танцееваю/танцееваешь.

\section{МЕЖЬЯЗЫКОВАЯ ИНТЕРФЕРЕНЦИЯ В АСПЕКТЕ ЛИНГВОДИДАКТИКИ}

Межъязыковая интерференция в лингводидактическом контексте понимается как отрицательное явление, создающее условия для появления в использовании языка ошибок.

Положительный перенос языковых единиц, трансфер, наоборот способствует изучению иностранного языка.

При сопоставлении лексики словацкого и русского языков разграничивают явления:

1.совпадающие в обоих языках по форме и содержанию (brat-бpam, park - napк, otec-oтеu, тата-мама, иlica-улица, с̌аj-чай, дег̆-день),

2.частично совпадающие в языках по выражению (album-aльбом, adresa-adpec, apríl-aпрель, problém-проблема),

3.несовпадающие по выражению в обоих языках (lekár - врач, byt - квартира, krok-шаг, mesto-город, prázdniny - каникуль).

Указанные связи возникают как результат близости двух родственных языков: словацкого и русского. Этот трансфер учитывается при обучении иностранного языка в словацкой среде: можно предположить одиниково функционирующие единицы, тексты. Полная эквивалентность упрощает также процесс коммуникации.

Лингводидактическое описание лексики в аспекте языковых контактов учитывает не только лингвистическое сопоставительное исследование лексики (основное положение: слово как знаковая единица владеет внешней и внутренней стороной), но и дидактическое значение при усвоении иностранного языка. Главным образом, необходимо соблюдать принципы лингводидактического описания с учетом практических целей (Rogal' 1994) обучения.

Используя ономасиологический подход с учетом возможной интерференции можно выделить следующие виды отрицательного переноса: 
1. Перенос деривационной парадигмы словацкого языка на русский: Книгу можно одолжсить в книжнице (в библиотеке); В здании просторное сходиште (лестница).

2. Перенос отсубстантивных мотивированных наименований: Когда идет дождь, надо иметь даждник (зонтик); читать читанку (хрестоматию); писать в писанке (тетрадь).

3. Перенос мотиванта словацкого языка, образуя лексический гибрид: $B$ нашей едални (столовая) можно хорошо покушать; я взял свой утерак (полотенце).

4. Перенос словацкого мотиванта на место русской непроизводной единицы: $3 a$ лекарством нужно ехать в лекарень (аптеку); Гости приехали в предвечер (накануне) праздника.

5. Перенос сложных наименований словацкого языка в русский на основании их совпадения по семантике и форме: добросрдечный (добросердечный) человек; двойместное (двухместное) купе; испорченный (водопровод) водовод.

Ocобое место в наборе интерференционных ошибок занимают слова, т.н. межъязыковые омонимы, которые усложняют процесс усвоения русского языка: $\boldsymbol{b} a \boldsymbol{n} \boldsymbol{a}-p y d-$ ник, шахта, копь, баня - parný kúpel', banka - банк; banka dát, údajov - база данных; колба, банка - pohár; plechovka; fl’aša; piesočný nános; piesočná plytčina; banka; lavica (v člne); sedadlo; skriňa; plytčina, batoh - узел (вещевой), сумка на спине, батог - chabina, palica; bič, bаza -бузина, база - základňa; stredisko; báza; sklad; základ; rázvor; zásobovacie stredisko; základná adresa; zásada, básen̆ -стихотворение, поэма, басня - bájk; dohádat' sa - кончить спор, догадаться - domysliet' si, dovtípit'sa; dohadovat' sa, hádat'sa - cnopumb, догадываться - prichadzat' na čo, domýšl'at' si; dohrýzt' - uскусать (pohrýzt'); npeкратить кусать, догрызть - hrýzt' pred koncom).

\section{РЕЗУЛЬТАТЫ И ДИСКУССИЯ}

Интерференция в процессе усвоения иностранного языка является объективным атрибутом. На практике необходимо добиться минимализации ошибок как последствия влияния родного языка на изучаемый. Одним из таких приемов является семантизация лексики, используя антонимы (истина - ложь, мужчина -женщина, трудный -легкий). Далее используются синонимические пары, синонимические эквиваленты, совпадающие частично или полностью (пес, собака - pes, nерстень, кольцо - prsteň), хотя семантизация через синонимические ряды может усложняться, потому что сложна сущность самой лексической синонимии.

Одним из эффективных методов выявления специфики русско-словацкой омонимии является межъязыковое сопоставление омонимических пар, поиск подходящих эквивалентов, использование в разных ситуациях общения.

В учебнике «Дидактика русского языка» (Petrikova, Kuprina, Gallo 2013) мы приводим систему упражнений, которые целесообразно использовать с целью минимизации лексической интерференции:

- переведите на родной язык предложения, составленные с разными значениями слов, но с одинаковой формой (возможен иной вариант: с одинаковым значением и разной формой), например: Свадебное платье напоминает наряд сказочной королевы. Купите бельй костюм классического фасона. У нас вы можете купить стильные платья девочке по низкой иене. Наряды - это документы, которыми может быть начислена 
заработная плата. После наряда, то есть распоряжений по работам завтрашнего дня, Коля вернулся к своему деду. Солдат получил наряд вне очереди.

- Подбор к словам антонимов.

*К словам из правого столбика подберите антоним из левого стобика:

снимать развязать

одевать продавать

застёгивать расстёгивать

покупать раздевать

завязать надевать

*Прочитайте диалог и подчеркните слова с противоположным значением:

Знаешь, - говорит Мишутка, - раньше я был большой большой, как дядя Боря, а потом сделался маленький.

- А я, - говорит Стасик, - сначала был маленький, а потом вырос большой, а потом снова стал маленький, а теперь опять скоро буду большой.

- А я, когда был большой, всю реку мог перепльть, - говорит Мишутка.

(N. N. Nosov "Fantazyory")

С целью предупреждения таких ошибок целесообразно проводить работу в выборе между контактирующими конструкциями.

*Прочитайте отрывок из рассказа Н. Н. Носова «Фантазёры. Найдите глаголы думать, выдумать и определите их значение.

- А ты думаешь, легко выдумыльать!

- Чего проще!

- Ну, вылумай что-нибудь.

- Сейчас... - сказал Игорь. - Пожалуйста.

Мишутка и Стасик обрадовались и приготовились слушать.

- Сейчас, - повторил Игорь. - Э э э... гм... кхм... э э э...

- Ну, что ты всё «э» да «э»!

- Сейчас! Дайте подумать.

- Ну, думай, думай!

- Э э э, - снова сказал Игорь и посмотрел на небо. - Сейчас, сейчас... э э э...

- Ну, чего же ты не выдумывваешь? Говорил - чего проще!

- Сейчас... Вот! Один раз я дразнил собаку, а она меня изап за ногу и укусила. Вот даже шрам остался.

- Ну и что же ты тут выдумал? - спросил Стасик.

- Ничего. Как было, так и рассказал.

- А говорил - вылумыввать мастер!

(N. N. Nosov "Fantazyory")

* Составьте словосочетания:

трудный чемодан

опасный путь

тяжёлый день

Цель следующего упражнения - выделить слова из тематической группы, которые служат источником интерферентных ошибок из-за незнания значения членов ряда. *Из данной тематической группы выберите слово, которое туда не входит: 
платье, наряд, костюм, валенки (валенки)

брюки, шортыл, кофта, джинсы (кофта)

брюки, джинсы, шортыл, рейтузы (рейтузы)

фрак, смокинг, платье, пижама (пижама)

\section{ЗАКЛЮЧЕНИЕ}

Итак, для словацких обучаемых характерен искусственный билингвизм, в условиях которого наблюдается интерференция, конкретно - это лексическая интерференция, под которой понимаются случаи отклонения от нормы, наблюдаемые в речи билингва на вторичном языке, связанные с нарушением категориальных признаков лексических единиц и возникающие под влиянием соответствующих категорий первичного языка. Сложности лексико-семантических отношений единиц словацкого и русского языков влияют на процесс усвоения русского языка, несмотря на то, что контактирующие языки близкородственные. С целью редукции явлений интерференции необходимо использовать языковые и речевые упражнения, которые создают единую систему соответствующей учебным целям. При рассмотрении лексики, ее совпадения или безэквивалентности в словацком и русском языках, необходимо учитывать сопоставление отношений в лексике обоих языков на парадигматическом уровне, а также использовать ономасиологический подход.

\section{REFERENCES}

Vajnrajh, U. (1979). Jazykovye kontakty. [Sostojanie i problemy issledovanija. Language contacts. State and problems of a research]. Per. s angl. Ju.A. Zhluktenko. Kiev: Vishha shkola. Izd-vo pri Kievskom universitete.

Zhluktenko, Ju. A. (1966). Movni kontakti. [Language contacts]. Kiev: Vid-vo Kï̈v. un-ta. Zhluktenko, Ju. A. (1974). Lingvisticheskie aspekty dvujazychija. [Linguistic aspects of bilingualism]. Kiev: Vishha shk. Izd-vo pri Kiev. un-ta.

Karlinskij, A. E. (1972).Tipologija rechevoj interferencii. [Typology of a speech interference] // Zarubezhnoe jazykoznanie i literatura. [Foreign linguistics and literature]. Vyp. 2. Alma-Ata, 9-10

Kurbanova, K. I. (2012). Mezhjazykovaja semanticheskaja interferencija (na materiale francuzskogo, anglijskogo i russkogo jazykov). [An interlingual semantic interference (on material of the French, English and Russian languages] // Uchenye zapiski Orlovskogo gosudarstvennogo universiteta. [Scientific notes of the Oryol state university]. Orel: Orl. gos. un-ta.

Medzinárodná organizácia migrantov. [International organization of migrants]. URL: https://iom.sk/sk/migracia/migracia-na-slovensku- Data obrashhenija: 12.01.2019.

Petríková, A. - Kuprina, T. - Gallo, J. (2013). Didaktika ruštiny. I. [Russian didactics I]. Prešov: Prešovská univerzita v Prešove.Filozofická fakulta.

Rogal', M. (1994). Bilingval'noe opisanie leksicheskogo aspekta jazykov v uchebnyh celjah. [The bilingual description of lexical aspect of languages in the educational purposes]. Nitra: Vysoká škola pedagogická v Nitre.

Rozencvejg, V.Ju. (1972). Jazykovye kontakty. [Language contacts]. Leningrad.: Nauka, 1972. 
Haugen, Je. (1972). Jazykovoj kontakt. [Language contact]. // Novoe v ligvistike. [New in a ligvistika]. Sostavlenie, redakcija, vstupitel'naja stat'ja i kommentarij: V. Ju. Rozencvejg. Moskva: Progress.

Shherba, L.V. (1974). Jazykovaja sistema i rechevaja dejatel'nost'. [Language system and speech activity]. Leningrad.: Vysshaja shkola.

Weinreich, U. (1999). Languages in Contact. V serii «Zarubezhnaja lingvistika». [Foreign linguistics] Moskva: Progress, t. 3.

Information about the author: Anna Petrikova, PhD. Assistant Professor, Department of Russian Studies, Faculty of Philosophy of Preshov University. Professor of the Russian Academy of Natural History (Moscow), Coordinator of the Erazmus + Program of the Institute of Russian Studies at the Faculty of Applied Physics in the Preshov, coordinator of student research activities, member of Slovak-Russian public organization in Slovakia (Slovakia)

Сведения об авторе: Анна Петрикова, доктор философии, ассистент-профессор кафедры русистики Философского факультета Прешовского университета (Словакия). Профессор Российской Академии \Естествознания (Москва). Координатор программы Erazmus + кафедры русистики ФФ ПУ в Прешове. Координатор студенческой научной деятельности, член Словацко - русской общественной организации в Словакии (Словакия)

Manuscript received: $12 / 08 / 2018$

Accepted for publication: $01 / 25 / 2019$

Рукопись получена: 01/08/2018

Принята к печати: 01/25/2019 